\section{$40 /(1)^{2}$}

PPPL-2845

UC-420

IMPROVED NUMERICAL GRID GENERATION TECHNIQUES

FOR THE B2 EDGE PLASMA CODE

BY

D.P. STOTLER, AND D.P. COSTER

June, 1992

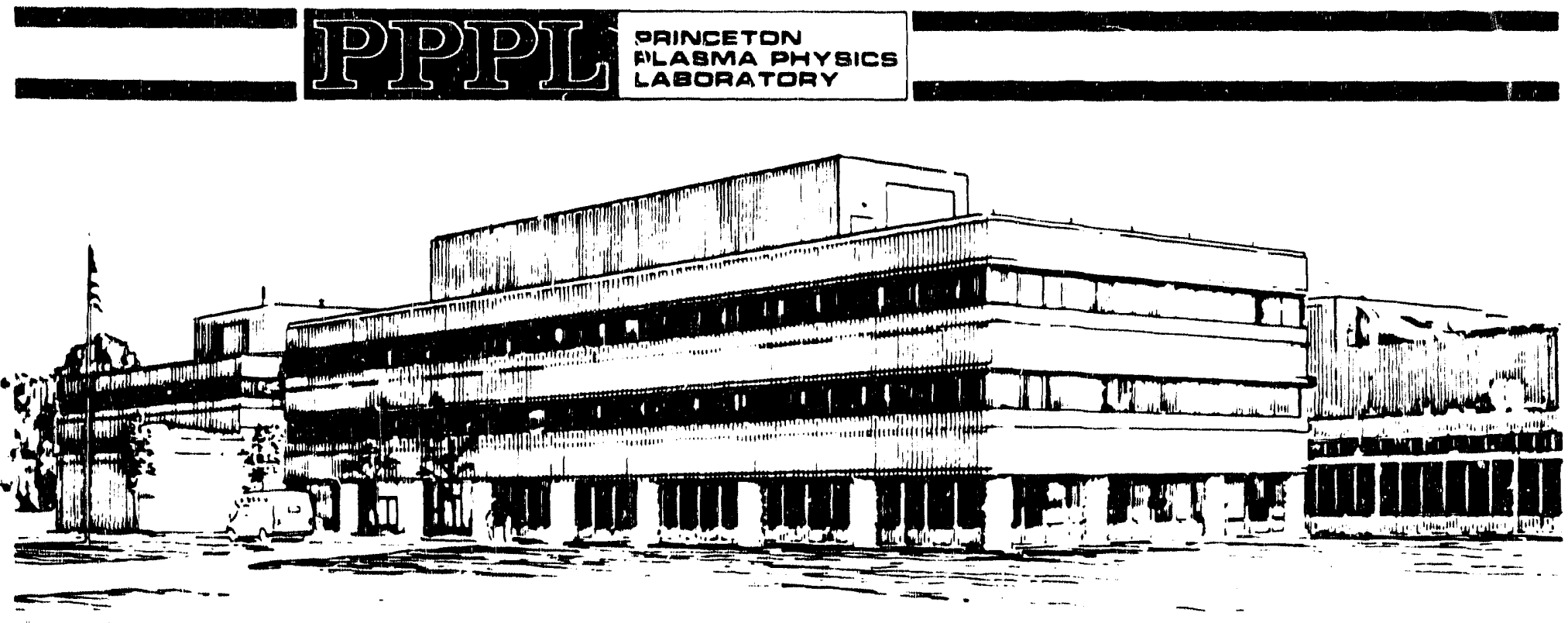




\section{NOTICE}

This report was prepared as an account of work sponsored by an agency of the United States Government. Neither the United States Government nor any agency thereof, nor any of their employees, makes any warranty, express or implied, or assumes any legal liability or responsibility for the accuracy, completeness, or usefulness of any information, apparatus, product, or process disclosed, or represents that its use would not infringe privately owned rights. Reference herein to any specific commercial produce, process, or service by trade name, trademark, manufacturer, or otherwise, does not necessarily constitute or imply its endorsement, recommendation, or favoring by the United States Government or any igency thereof. The views and opinions of authors expressed herein do not necessanily state or reflect those of the United States Government or any agency thereot.

\section{NOTICE}

This report has been reproduced directly from the best available copy.

Available to DOE and DOE contractors from the:

Office of Scientific and Technical Information

P.O. Box 62

Oak Ridge, TN 37831 ;

Prices available from (615) 576-8401.

Available to the public from the:

National Technical Information Service

U.S. Department of Commerce

5285 Port Royal Road

Springfield, Virginia 22161

703-487-4650 
PPPL- -2845

DE92 015162

\title{
Improved Numerical Grid Generation Techniques for the B2 Edge Plasma Code
}

\author{
D. P. Stotler and D. P. Coster \\ Princeton Plasma Physics Laboratory \\ Princeton University \\ Princeton, New Jersey 08543
}

\begin{abstract}
Techniques used to generate grids for edge fluid codes such as B2 from numerically computed equilibria are discussed. Fully orthogonal, numerically derived grids closely resembling analytically prescribed meshes can be obtained. But, the details of the poloidal field can vary, yielding significantly different plasma parameters in the simulations. The magnitude of these differences is consistent with the predictions of an analytic model of the scrape-off layer. Both numerical and analytic grids are insensitive to changes in their defining parameters. Methods for implementing nonorthogonal boundaries in these meshes are also presented; they differ slightly from those required for fully orthogonal grids.
\end{abstract}




\section{Introduction}

Until recently, the only method available for generating computational meshes for use in the B2 edge plasma fluid code ${ }^{1}$ has been an analytic con* formal mapping technique. Although the resulting grid is fairly smooth and computationally robust, it is difficult to obtain an exact match to an externally computed equilibrium. Furthermore, the effort required to specify the parameters in the algorithm prevents new meshes from being generated as frequently as needed. These concerns have led us to develop procedures for deriving $\mathrm{B} 2$ grids directly from numerical equilibria; ${ }^{2}$ this work is similar to that performed earlier. ${ }^{3-5}$

Simulations of Burning Plasma Experiment ${ }^{6}$ (BPX; formerly the Compact Ignition Tokamak) using $\mathrm{B} 2$ with an initial numerical ${ }^{7}$ grid did not match those resulting from a corresf onding conformal map mesh, despite the fact that the two grids were basea on the same equilibrium. Initial improvements to the numerical mesh gene:ation procedure gave rise to $\mathrm{B} 2$ runs which did not converge under the same conditions as did the previous cases. These difficulties led us to investigate inore closely the techniques used to generate $\mathrm{B} 2$ numerical meshes and to examine the differences between them and the corresponding conformal map grids.

The first step in the mesh generation procedure is carried out by a separate code; ${ }^{2}$ we will not consider chan es to it here. Instead, we will focus on the manner in which B2 interpolates its mesh from the preliminary grid computed in this first step. In Sec. II, we will demonstrate a method for obtaining a grid that is as close to the corresponding conformal map mesh as possible. Despite the visual similarity of the grids, differences persist in the resulting $\mathrm{B} 2$ simulations. These originate from small variations in the equilibria represented by the two grids; an analytic scaling for the peak divertor heat flux in terms of geometrical quantities provides a good description of these variations. We consider in Sec. III the sensitivity of B2 results to changes in the parameters used to define the grids. For typical paramete: s, little sensitivity is found. The need to accurately incorporate the material boundaries of fusion de vices leads us to consider also meshes which are not fully orthogonal. We demcistrate in Sec. IV how the techniques of Sec. II can be altered to properly treat these grids. Finally, we present in Sec. V our conclusions. 


\section{Comparing Numerically and Analytically Generated Grids}

The procedure for generating a B2 grid from a numerically computed equilibrium consists of two pieces. The first is carried out by a separate code. $^{2}$ This routine begins by reading a file containing the MHD equilibrium information, namely, the values of the magnetic flux on a mesh in physical $R$ (the major radius) and $Z$ (height with respect to the tokamak midplane) space. Individual flux surface shapes are determined from these data, and the $\mathrm{X}$-point, if present, is located. Coordinate surfaces perpendicular to the flux surfaces are set up. Finally, material boundary specifications are taken into account. If nonorthogonal grids are desired, the perpendicular surfaces near the target boundary are pushed back along the field lines until they conform. $^{2}$

The $R$ and $Z$ coordinates of the $1 \leq i x^{\prime} \leq n x^{\prime}$ (along flux surfaces) by $1 \leq i y^{\prime} \leq n y^{\prime}$ (across flux surfaces) points comprising the preliminary grid are written to a file. In addition, the components of the magnetic field vector $B_{R}, B_{Z}$ and $B_{\phi}$ (toroidal) at each grid point are recorded.

The second piece of the grid generation procedure is carried out at the start of $\mathrm{B} 2$ and begins with the reading of the file containing the preliminary grid. The $\mathrm{B} 2$ code interpolates from this (usually very fine) grid a somewhat rougher version on which the $\mathrm{cc}^{+}$ual calculations will be done. The grid indices for the final computational mesh range over $0 \leq i x \leq n x+1(0 \leq$ iy $\leq \mathrm{ny}+1)$. The values of $\mathrm{nx}$ and $\mathrm{ny}$ are input when $\mathrm{B} 2$ is run.

Two steps are required to generate the final B2 grid. First, the integer indices of the input grid must be mapped onto on a real interval using some continuous function. Second, the integers labeling the final grid must be mapped onto the same interval. Then, simple interpolation techniques can be used to determine the $R, Z$, and $\mathbf{B}$ values at each of the final grid points. Note that the two mapping functions need not be related.

A good mesh should have a smoothly varying spacing between grid points; there are some indications that numerical calculations are more well-behaved under these conditions. ${ }^{9}$ Since smoothness is one of the virtues of the analytically derived conformal map mesh and since we are attempting to match as closely as possible the $\mathrm{B} 2$ results it yields, we endeavor to duplicate in the 
numerically generated grid the $x$ and $y$ spacing of the conformal map mesh.

At this point, we define $x$ and $y$ more precisely. We denote by $x$ the poloidal distance along a fixed reference flux surface and by $y$ the distance along some reference line in the perpendicular direction. We design the numerical grid interpolation procedure so that it will yield $x$ and $y$ arrays that closely match those of the analytic grid. For a symmetric double null geometry, we define the functions mapping $i x^{\prime}$ and $i y^{\prime}$ of the preliminary mesh on to the real line as the distance along the separatrix, $x^{\prime}\left(i x^{\prime}\right)$, and the distance along midplane relative to the separatrix, $y^{\prime}\left(i y^{\prime}\right)$, respectively.

The second step in generating the final $\mathrm{B} 2$ grid makes use of a general interpolation procedure (also employed in producing the conformal map grid ${ }^{10}$ ) which smoothly interpolates a function between two points with specified first derivatives at each end. The interpolation function is actually a composition of three functions. ${ }^{10}$ The most basic element is

$$
g_{b a s e}\left(t ; g_{0}, g_{1}, g_{0}^{\prime}\right) \equiv g_{0}+\left(g_{1}-g_{0}\right) t\left[\frac{g_{0}^{\prime}}{g_{0}^{\prime} t+\left(g_{1}-g_{0}\right)(1-t)}\right]
$$

$g_{\text {base }}$ has the properties:

$$
\begin{aligned}
g_{\text {base }}(t=0) & =g_{0}, \\
g_{\text {base }}(t=1) & =g_{1}, \\
\left.\frac{\partial g_{\text {base }}}{\partial t}\right|_{t=0} & =g_{0}^{\prime} .
\end{aligned}
$$

This function is monotonic provided $g_{0}^{\prime}\left(g_{1}-g_{0}\right)>0$.

One of these base functions is set up at each end of the desired interpolation interval. We denote them by $g_{b a s e, 0}$ and $g_{b a s e, 1}$. They can be combined in a smooth manner using the function

$$
h_{w t}\left(u ; g_{b a s e, 0,} g_{b a s e, 1}\right) \equiv g_{b a s e, 0} \cos ^{2}\left(\frac{\pi}{2} u\right)+g_{b a s e, 1} \sin ^{2}\left(\frac{\pi}{2} u\right)
$$

Namely, this weighting function has the properties

$$
\begin{aligned}
& h_{w t}(u=0)=g_{\text {base }, 0}, \\
& h_{w t}(u=1)=g_{\text {base }, 1},
\end{aligned}
$$




$$
\begin{aligned}
& \left.\frac{\partial h_{w t}}{\partial u}\right|_{u=0}=\left.\frac{\partial g_{\text {base }, 0}}{\partial u}\right|_{u=0}, \\
& \left.\frac{\partial h_{w t}}{\partial u}\right|_{u=1}=\left.\frac{\partial g_{\text {base }, 1}}{\partial u}\right|_{u=1} .
\end{aligned}
$$

Thus, the values and derivatives of the base functions are retained at each endpoint, and $h_{w t}$ varies smoothly in between.

Finally, the interpolating function can be defined in terms of $g_{b a s e}$ and $h_{w t}$,

$$
\begin{aligned}
f_{\text {interp }}\left(v ; v_{a}, f_{a}, f_{a}^{\prime}, v_{b}, f_{b}, f_{b}^{\prime}\right) & \equiv h_{w t}\left(\frac{v-v_{a}}{v_{b}-v_{a}}, g_{b a s e, 0}, g_{b a s e, 1}\right), \\
g_{b a s e, 0} & \equiv g_{b a s e}\left[\frac{v-v_{a}}{v_{b}-v_{a}}, f_{a}, f_{a}^{\prime}\left(v_{b}-v_{a}\right), f_{b}\right], \\
g_{\text {base }, 1} & \equiv g_{\text {base }}\left[\frac{v_{b}-v}{v_{b}-v_{a}}, f_{b},-f_{b}^{\prime}\left(v_{b}-v_{a}\right), f_{a}\right] .
\end{aligned}
$$

Hence, $f_{\text {interp }}$ has the desired features:

$$
\begin{aligned}
f_{\text {interp }}\left(v_{a}\right) & =f_{a}, \\
f_{\text {interp }}\left(v_{b}\right) & =f_{b}, \\
\left.\frac{\partial f_{\text {interp }}}{\partial v}\right|_{v=v_{a}} & =f_{a}^{\prime}, \\
\left.\frac{\partial f_{\text {interp }}}{\partial v}\right|_{v=v_{b}} & =f_{b}^{\prime} .
\end{aligned}
$$

Furthermore, $f_{\text {interp }}$ is monotonic if $f_{a}^{\prime}, f_{b}^{\prime}$, and $f_{b}-f_{a}$ all have the same sign.

We divide the $x$ array into two pieces, one above the X-point and one below. Likewise, the $y$ array is divided into two sections, one inside the separatrix and one outside. In defining the interpolation functions for $x$, we take from a BPX conformal map mesh the values of $x$ at each endpoint of the two segments; these become the $v_{a}$ and $v_{b}$ values in Eq. (5). We also note the widths $\Delta x$ of the first and last zones, $\Delta x_{a}$ and $\Delta x_{b}$, of each segment. All of these lengths are rescaled to match the corresponding lengths in the preliminary numerical mesh, allowing this BPX conformal map mesh to serve as a general template for all numerically generated symmetric double null grids. Of course, these length parameters can be altered to match those 
of some other reference mesh. We use in Eq. (5) $f^{\prime}\left(v_{a}\right)=\Delta x_{a} n x_{c m}$, and $f^{\prime}\left(v_{b}\right)=\Delta x_{b} n x_{c m}$, where $a x_{c m}$ is the number of grid points used in the reference conformal map. For points in the first half of the final B2 grid (ix $\leq n x / 2$ ), the parameters for the segment above the X-point are used. In the second half, the segment below the X-point provides the $v_{a}$ and $v_{b}$. An analogous procedure provides the two interpolation functions needed for $y$.

Completely defining the final B2 grid is a somewhat involved procedure since all cell corners and cell centers must be specified. As B2 goes through this process, it requests the $R$ and $Z$ coordinates corresponding to each "(ix, iy)" pair (which are not necessarily integers) it requires. Values for $x$ and $y$ are obtained for this pair from the inte: polation functions described above. By comparing these $x$ and $y$ against $x^{\prime}\left(i x^{\prime}\right)$ and $y^{\prime}\left(i y^{\prime}\right)$, the nearest $i x^{\prime}$ and $i y^{\prime}$ from the preliminary mesh can be identified. The $R$ and $Z$ coordinates are then determined by a simple 2-D linear interpolation scheme. The interpolation information is used again to set the values of the three components of $\mathbf{B}$.

We show as an example the complete B2 scrape-off layer mesh for a standard BPX equilibrium ${ }^{6}$ in Fig. 1. An enlargement of the region near the divertor is shown in Fig. 2; this should be compared with the corresponding plot for the analytic conformal map mesh, Fig. 3. Note that the parameters defining the conformal map were set so as to match as closely as possible the same numerical equilibrium upon which the preliminary grid is based. The total width in $y$ for the two grids is different (this can be altered in the preparation of the preliminary mesh); nonetheless, the two meshes are visually similar.

We now begin to compare the two grids on a quantitative basis. One of the important geometric quantities in scrape-off layer physics is the connection length

$$
L_{\|}=\int d x_{p} \frac{B}{B_{p}}
$$

where $x_{p}$ is the distance in the poloidal plane along along a flux surface and $B_{p}$ is the poloidal magnetic field. A related parameter appears in analytic descriptions of scrape-off layer behavior, ${ }^{8}$

$$
G \equiv \int d r_{p} 2 \pi R^{2} B_{p}
$$


For example, the Barr model ${ }^{8}$ predicts that the peak heat flux $q_{\max }$ scales as

$$
q_{\max } \propto B_{p, d i v} G^{-7 / 9} L_{\|}^{-2 / 9}
$$

where $B_{p, d i v}$ is the value of the poloidal field at the divertor plate. The quantities $L_{\|}, G$, and $B_{p, d i v} G^{-7 / 9} L_{\|}^{-2 / 9}$ provide rough bases for comparing meshes.

In Table I, we present the values of these parameters for the two grids in Figs. 2 and 3 along flux surfaces iy $=7$ and 15 (ny $=24$; separatrix is the boundary between $i y=6$ and 7 ). It is clear that noticeable differences persist in the parameters despite the visual similarity of the figures. The discrepancies in Table I result instead from variations in the poloidal field. Namely, the equilibria represented by the two grids are slightly different (for example, this might indicate that the equilibrium described by the conformal map is not exactly the same as the one from which it is derived).

In comparing the results of B2 runs (with reference BPX parameters ${ }^{6}$ ) using the two grids, we find that the scaling Eq. (9) accurately reflects (to within $\sim 5 \%$ ) the differences in Table I. We conclude that even though these meshes appear to be very similar, small deviations in the poloidal field values (particularly near the X-point and divertor plate) can arise, yielding significant discrepancies in the peak heat flux.

This point is relevant to comparisons of different numerical equilibria as well. During BPX operation, the strike point will be swept over the divertor in order to more evenly spread the heat flux. ${ }^{6}$ The consequent differences in the equilibria are capable of giving rise to noticeable differences in the peak heat fluxes even when the same core plasma assumptions are used. As an example, we show in Figs. 4 and 5 equilibria from the beginning and end, respectively, of the BPX divertor sweep (note the different $R$ and $Z$ scales in the figures). In both cases, the divertor plate is defined as an orthogonal surface $15 \mathrm{~cm}$, along the separatrix, from the X-point. In Table II we compare the geometrical parameters for these equilibria. The differences here are smaller than those noted in Table I, but are still significant. Again, B2 runs performed on these two equilibria using the same input parameters yield values for the peak heat flux which scale reasonably well with $B_{p, \text { div }} G^{-7 / 9} L_{\|}^{-2 / 9}$ according to Eq. (9). Given the importance of the peak heat flux in evaluating divertor performance, ${ }^{6}$ it would be prudent to carry out B2 runs to 
simulate multiple operating points during a BPX discharge. On the other hand, the overall uncertainties associated with these calculations could very well be much larger than these geometric differences. ${ }^{6}$

\section{Sensitivity to Grid-Defining Parameters}

In this section, we examine the extent to which the details of the B2 grid impact the results. One would like to find that the outcome of the calculations is insensitive to variations in the parameters defining the B2 grid. For this discussion, we utilize both numerically and analytically generated grids.

We first consider alterations in the values of $\Delta y$ on either side of the separatrix in the numerical grid. In this case, the geometric parameters listed in Table I do not change noticeably. We assume that the results of a $\mathrm{B} 2$ run would follow suit. Varying the value of $\Delta x$ above and below the $\mathrm{X}$-point in both the numerical and conformal map grids does not lead to substantial changes in the geometric parameters either. B2 runs with BPX parameters confirm that the simulation results are insensitive as well.

Next, we examine the sensitivity to ny. The value of $\Delta y$ is varied proportionately. Raising ny from 24 to 48 for the numerical grid leads to differences in BPX plasma parameters at the plate of a few percent (except for the peak particle flux which changes by $\sim 16 \%$ ). Doing likewise for the conformal map, we again find differences in BPX divertor plasma parameters of no more than a few percent. We thus conclude that these B2 runs are reasonably well converged in ny at ny $=24$.

Finally, we consider variations in $\mathrm{nx}$ with the numerical grid (holding all $\Delta x$ values fixed). In Figs. 6 and 7 , we show the electron temperature and density variation along the field line near the plate in several runs of B2 using BPX reference parameters; $\mathrm{nx}$ ranges from 16 to 80 . It appears that convergence in $n x$ is rather poor, particularly with regard to the density.

The standard analytic neutral transport model ${ }^{1}$ used in B2 employs a limit on the ion source rate in the two zones closest to the plate (ix $=n x-1$ and $n x$ ); this limitation is required in general to ensure that B2 can obtain a solution. If $n x$ is large enough the limit is not exceeded; so, the results should converge as $n x \rightarrow \infty$. However, when the limit is in effect, an intrinsic 
dependence on the number of grid points is introduced into the problem, and unphysical variations in plate parameters with $n \times$ result, as is exemplified by Figs. 6 and 7.

For this particular set of parameters, the source rate limitation can be removed without affecting the ability of $\mathrm{B} 2$ to find a solution. We show in Figs. 8 and 9 plots from such simulations. The code reacts more smoothly to changes in $n x$ in this case. It is apparent from these plots that $n x \gtrsim 64$ is required to resolve properly the ion source rate near the plate and eliminate the sersitivity to $\mathbf{n x}$. But, $\mathbf{n x}=32$ is probably adequate for most applications when we consider that our understanding of the physics near the sheath is somewhat incomplete.

\section{Treatment of Grids with Nonorthogonal Boundary Conditions}

Thus far we have discussed meshes which are entirely orthogonal. Rarely is it the case, however, that the field lines in an actual device are normal to the divertor target plate or limiter. In fact, glancing incidence is common. ${ }^{11,12}$ In order to allow such situations to be modeled with a minimum of new code development, an approximate technique for treating nonorthogonal boundary conditions has been developed. ${ }^{2}$

The additional work required is done primarily in preparing the preliminary mesh. As in Sec. II, an orthogonal mesh is first established using the information from the numerical equilibrium. Additional data describing the material surfaces in closest proximity to the plasma are specified. We refer to the portion of this surface on which the sheath boundary condition will be established as the target surface. The orthogonal mesh is deformed by "pushing back" the (formerly) perpendicular grid surfaces along the field lines (which remain unaltered) until they conform to the shape of the target surface. The result is that each flux tube has at its end some number of very narrow (in the direction along the flux surfaces) zones; the number of narrow zones varies with the grid index along the target. The mesh remains orthogonal everywhere except in the immediate vicinity (much less than any distance scale of interest to B2) of this target surface.

The first application of this technique was in modeling the TFTR lim- 
iter. $^{2}$ The TFTR case is particularly severe in that the field lines are virtually parallel to the limiter surface near the device midplane. More recently, we have applied our method to simulations of BPX reference scenarios. Engineering specifications for the divertor and limiter shapes corresponding to the BPX reference equilibria discussed in Sec. II have been obtained and used in generating preliminary meshes for B2.

However, the procedures described in Sec. II for generating the final B2 mesh fail in this instance. The problem is that in the preliminary mesh, the distance between the perpendicular surfaces along the separatrix is very small for the very narrow zones near the target (by design). Some of the zones in the final mesh must be selected from within this short interval in order for the nonorthogonality to be properly resolved. There is no way in general to specify the parameters used in Sec. II to do this effectively.

The grid resolution required for accurate calculation of neutral transport behavior must also be considered. If the $\mathrm{B} 2$ grid is to be used in Monte Carlo neutral transport calculations,$^{13}$ the normal-size zones near the target must be sufficiently close together to resolve the ion source rate profile. Again, the interpolation functions described in Sec. II do not perform adequately in this regard.

Our solution to these problems is not too different from that of Sec. II. Instead of mapping $i x^{\prime}$ and $i y^{\prime}$ onto the real line using distance along the separatrix and midplane, we set up a simple linear map onto the interval $(0,1)$. In this manner, the densely packed zones near the target are treated on an equal footing with those of the orthogonal portion of the grid.

In the second step of preparing the final mesh, the interpolation function along the field lines is defined in three pieces instead of two. The break at the X-point remains. As before, the function is set up so that $n x / 2$ of the grid points fall above the $X$-point, and $n x / 2$ fall below. Now, however, the region between the $\mathrm{X}$-point and the target surface is divided again in two. This introduces four new variables into the problem.

One of these, the value of the interpolating function at the second break point, determines where in $R$ and $Z$ space the break point falls. In a divertor geometry, we locate this break near the separatrix stike point so that the size of the normal zones in that vicinity can be varied. Another parameter controls the corresponding value of $i x$. The remaining two parameters set 
the mesh spacing on either side of the break point. As before, the mesh spacing just below the X-point and at the target plate can be adjusted. The latter, however, is not very useful due to the packing of zones required by the nonorthogonal boundary condition. The mesh spacing above the X-point is arranged so as to blend as smoothly as possible into the spacing below the $X$-point, as w/as cione in Sec. II. One drawback to this revised procedure is that there is no automatic means of determining these mesh parameters in general; they must be chosen through a trial-and-error process.

The nonorthogonal BPX mesh corresponding to Fig. 5 is shown in Fig. 10. Note the reduced spacing between orthogonal cells near the intersection of the separatrix with the target plate. This grid features $n x=64$ rather than the $n x=32$ used elsewhere in this paper. An increased number of grids is required since several zones are essentially "wasted" in setting up the nonorthogonal boundary condition. The additional zones make up for the loss, maintaining at least 16 orthogonal zones between the target plate and the X-point.

Comparing B2 runs with the orthogonal and nonorthogonal grids shown in Figs. 5 and 10, we find very similar results. This may not be the case, however, with a Monte Carlo calculation of the neutral behavior. Namely, with the nonorthogonal grid we expect the neutral density to spread outward to a greater extent as a result of the inclined plate.

\section{Conclusions}

We have discussed in detail techniques for generating from numerically computed equilibria grids for use in edge fluid codes such as B2. Numerically derived grids closely resembling those obtained by analytic (conformal map) means can be produced. But, to the extent that details in the poloidal field values differ, simulation results vary. These variations are consistent with an analytic scaling. ${ }^{8}$

We have shown that both numerical and analytic grids are relatively insensitive to changes in their defining parameters. The most problematic of these parameters is the number of grid points along the field line. As it is changed, the mesh spacing near the target sheath is altered. Given that the plasma parameters (particularly the density) can vary rapidly in this 
region, one expects to find some sensitivity to mesh spacing of the plasma values immediately in front of the sheath. However, as the mesh spacing is made much smaller than the neutral mean free path, this sensitivity should diminish.

Finally, we have discussed techniques for implementing nonorthogonal boundaries in $\mathrm{B} 2$ grids. A slightly different mesh generation technique is required in this case. Although we obtain results similar to those found with orthogonal grids, we expect greater differences when a Monte Carlo neutral transport calculation is used.

\section{Acknowledgments}

This work was supported by U.S. DOE Contract No. DE-AC02-76-CHO3073. 


\section{References}

1. B. J. BRAAMS, “A Multi-Fluid Code for Simulation of the Edge Plasma in Tokamaks," EUR-FU/XII-80/87/68, Next European Torus (Jaruary 1987).

2. D. P. COSTER, M. G. BELL, B. J. BRAAMS, A. B. EHRHARDT, C. F. F. KARNEY, C. S. PITCHER, D. P. STOTLER, and M. ULRICKSON, "Edge Plasma Modeling of TFTR with the B2 2-D Fluid Code," Bull. Am. Fhys. Soc., 35, 2086 (1990).

3. M. PETRAVIC, "Orthogonal Grid Construction for Modeling of Transport in Tokamaks," J. Comp. Phys., 73, 125 (1987).

4. E. L. VOLD, F. NAJMABADI, and R. W. CONN, "Fluid Lodel Equations for the Tokamak Plasma Edge," Phys. Fluids B, 3, 3132 (1991).

5. M. RENSINK, Lawrence Livermore National Laboratory, Private Communication (1992).

6. R. J. GOLDSTON, G. H. NEILSON, D. B. BATCHELOR, G. BATEMAN et al., "Burning Plasma Experiment Physics Design Description," G. BATEMAN, Ed., X-910311-PPL-22, Burning Plasma Experiment, Princeton Plasma Physics Laboratory (March 1991); to appear in Fusion Technol. (1992).

7. D. P. STOTLER, B. J. BRAAMS, D. COSTER, A. B. EHRHARDT, C. F. F. KARNEY, and M. ULRICKSON, "Compact Ignition Tokamak Edge and Divertor Modeling," Bull. Am. Phys. Soc., 35, 1921 (1990).

8. W. L. BARR, "A Model for the Edge Plasma Near a Poloidal Divertor," Fusion Technol., 19, 498 (1991).

9. T. D. ROGNLIEN, Lawrence Livermore National Laboratory, Private Communication (1990).

10. B. J. BRAAMS, New York University Courant Institute of Mathematical Sciences, Private Communication (1989). 
11. C. S. PITCHER, P. C. STANGEBY, R. V. BUDNY, C. E. BUSH, J. D. ELDER et al., "Effect of the Boundary Plasma on TFTR Ohmic Discharges," Nucl. Fusion, 32, 239 (1992).

12. ITER COUNCIL, "ITER Conceptual Design Activities Final Report," ITER Documentation Series, No. 16, International Atomic Energy Agency (1991).

13. D. P. STOTLER, D. P. COSTER, B. J. BRAAMS, A. B. EHRHARDT, C. F. F. KARNEY, and M. PETRAVIC, "Scrape-off Layer Modeling Using Coupled Plasma and Neutral Transport Codes," to appear in $J$. Nucl. Mater. 


\begin{tabular}{|c|c|c|c|c|}
\hline & iy & $L_{\|}$ & $G$ & $B_{p, d i v} G^{-7 / 9} L_{\|}^{-2 / 9}$ \\
\hline Numerical Grid & 7 & 39.4 & 229. & 0.00151 \\
& 15 & 18.2 & 231. & 0.00235 \\
\hline Conformal Map & 7 & 27.8 & 255. & 0.00232 \\
& 15 & 15.3 & 257. & 0.00312 \\
\hline
\end{tabular}

Table I: Geometric scrape-off layer parameters; all units are MKS. Note that $i y=7$ is the zone immediately outside the separatrix; iy $=15$ is approximately one scrape-off width farther out.

\begin{tabular}{|c|c|c|c|c|}
\hline & iy & $L_{\|}$ & $G$ & $B_{p, \text { div }} G^{-7 / 9} L_{\|}^{-2 / 9}$ \\
\hline Sweep start & 7 & 37.0 & 239. & 0.00161 \\
& 15 & 17.4 & 241. & 0.00242 \\
\hline Sweep end & 7 & 45.4 & 250. & 0.00121 \\
& 15 & 19.1 & 254. & 0.00217 \\
\hline
\end{tabular}

Table II: Geometric scrape-off layer parameters for BPX reference equilibria at the beginning and end of the divertor sweep; all units are MKS. 


\section{Figures}

FIG. 1. Mesh for B2 numerically derived from an equilibrium computed for a standard BPX discharge. This represents the lower, outer quadrant of the scrape-off layer in an up-down symmetric double-null discharge.

FIG. 2. Enlargement of the divertor region in a B2 mesh numerically derived from an equilibrium computed for a standard BPX discharge.

FIG. 3. Enlargement of the divertor region in a B2 mesh obtained by the analytic conformal mapping procedure. The parameters of the conformal map are determined by comparison with a standard BPX equilibrium.

FIG. 4. B2 mesh numerically derived from an equilibrium computed for a standard BPX discharge at the beginning of the divertor sweep.

FIG. 5. B2 mesh numerically derived from an equilibrium computed for a standard BPX discharge at the end of the divertor sweep.

FIG. 6. Electron density near the plate is plotted as a function of distance along the field line for a flux surface just outside the separatrix (a) (iy = $7 ; \mathrm{ny}=24)$ and for one further out into the scrape-off layer $(\mathrm{b})$ (iy $=10$ ). The number of grid points in the poloidal direction $\mathrm{nx}$ is indicated in the legend. A BPX conformal map geometry is used.

FIG. 7. Electron temperature near the plate is plotted as a function of distance along the field line for a flux surface just outside the separatrix (a) (iy $=7$; ny $=24$ ) and for one further out into the scrape-off layer (b) (iy = 10). The number of grid points in the poloidal direction $n x$ is indicated in the legend. A BPX conformal map geometry is used.

FIG. 8. Electron density near the plate is plotted as a function of distance along the field line for a flux surface just outside the separatrix (a) (iy = $7 ; \mathrm{ny}=24)$ and for one further out into the scrape-off layer $(b)(i y=10)$. The number of grid points in the poloidal direction $n x$ is indicated in the legend. A BPX conformal map geometry is used; the restriction on the ion source in the cells adjacent to the plate is removed. 
FIG. 9. Electron temperature near the plate is plotted as a function of distance along the field line for a flux surface just outside the separatrix (a) (iy $=7 ; n y=24$ ) and for one further out into the scrape-off layer (b) $($ iy $=10)$. The number of grid points in the poloidal direction $n x$ is indicated in the legend. A BPX conformal map geometry is used; the restriction on the ion source in the cells adjacent to the plate is removed.

FIG. 10. Nonorhtogonal B2 mesh numerically derived from an equilibrium computed for a standard BPX discharge at the end of the divertor sweep. 


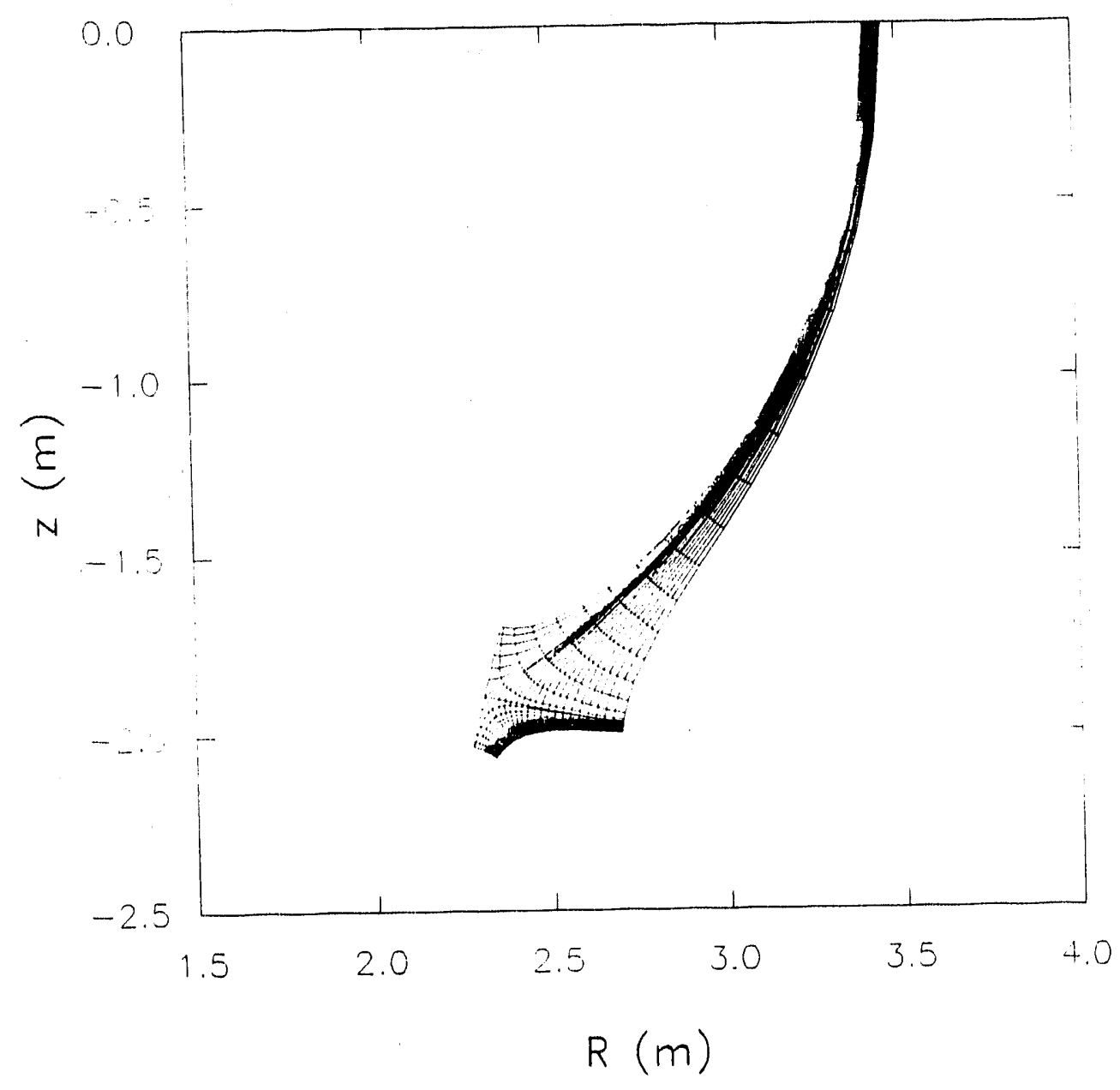

FIG. 1 


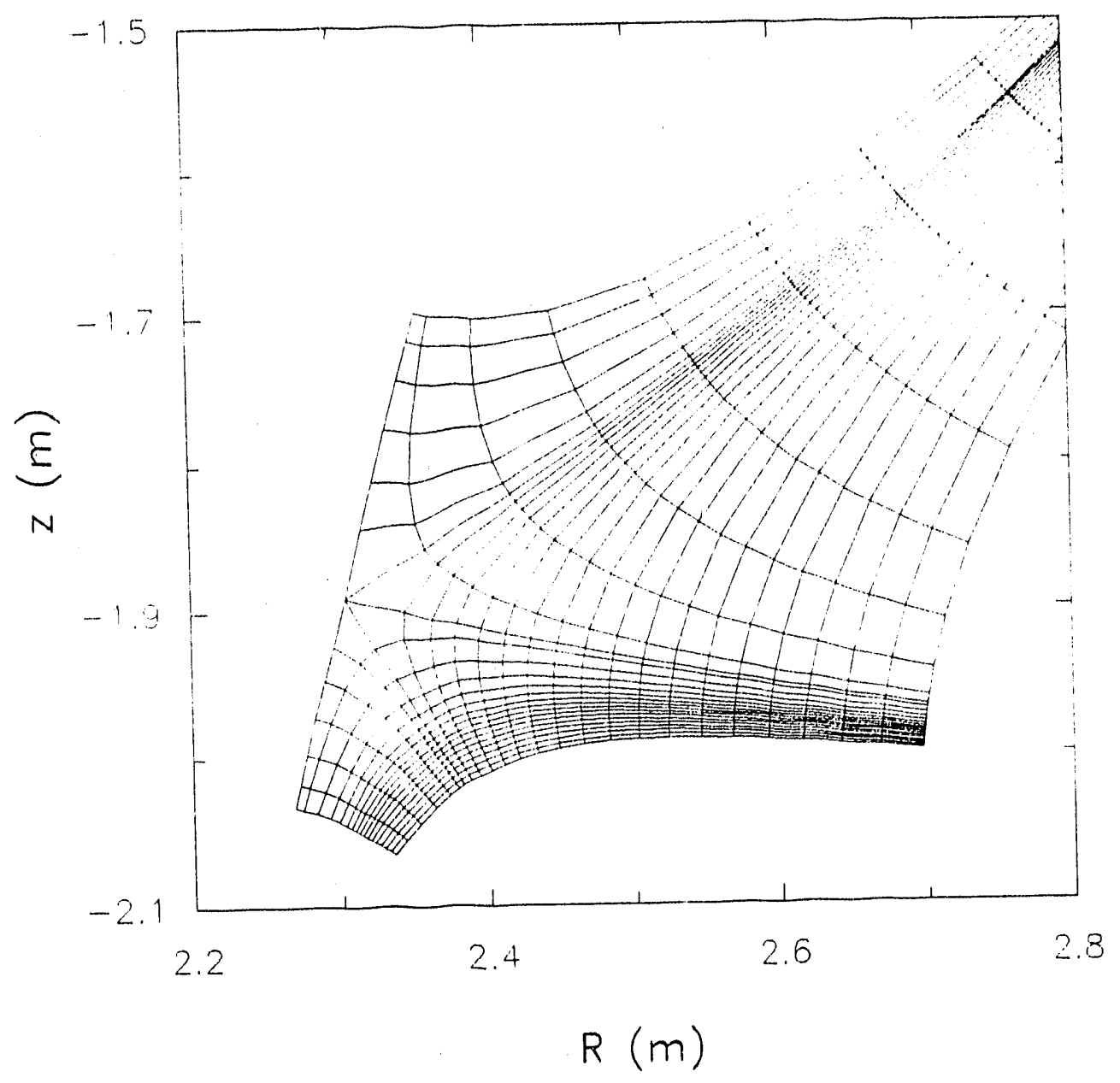

FIG. 2 


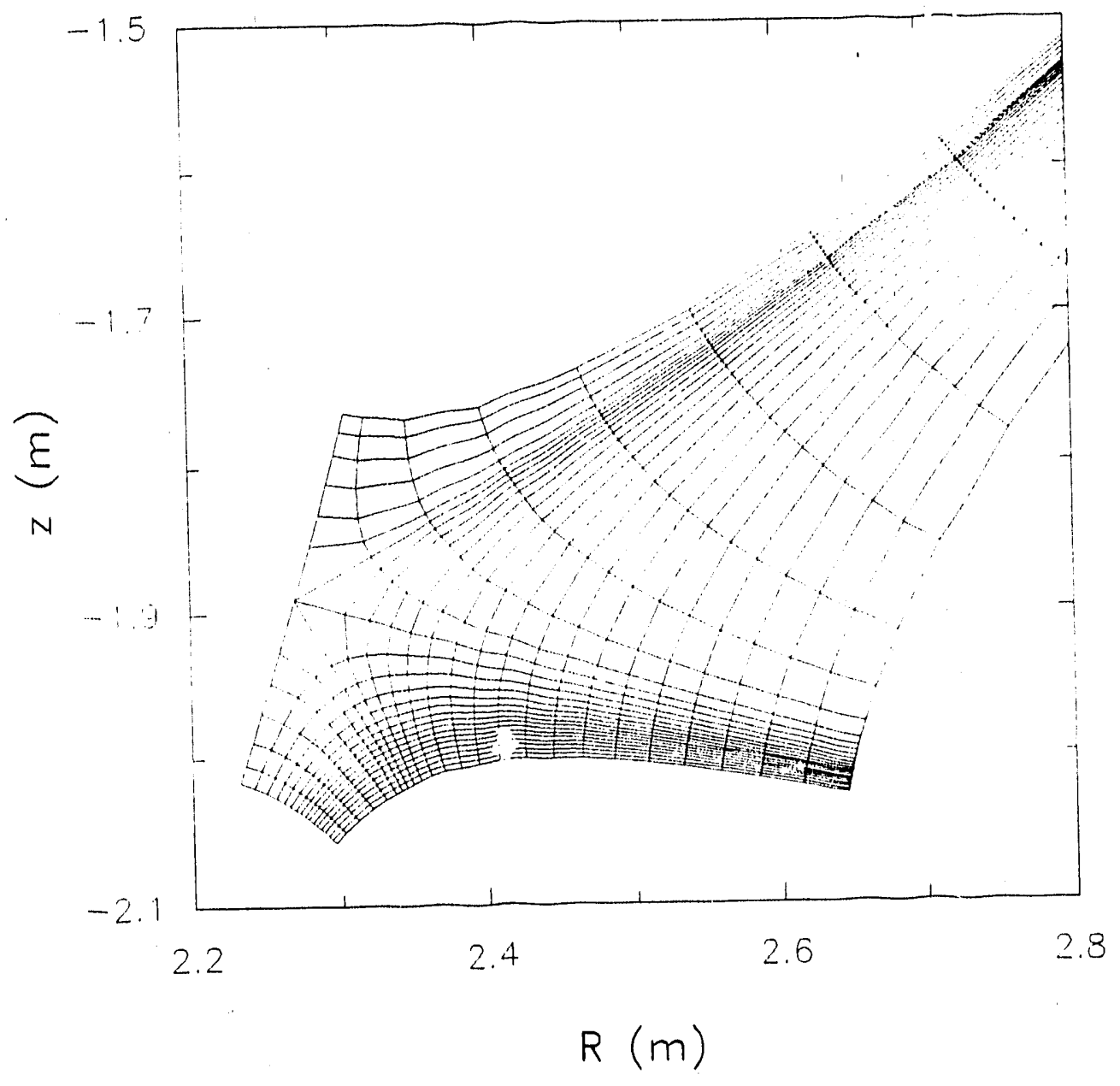

FIG. 3 


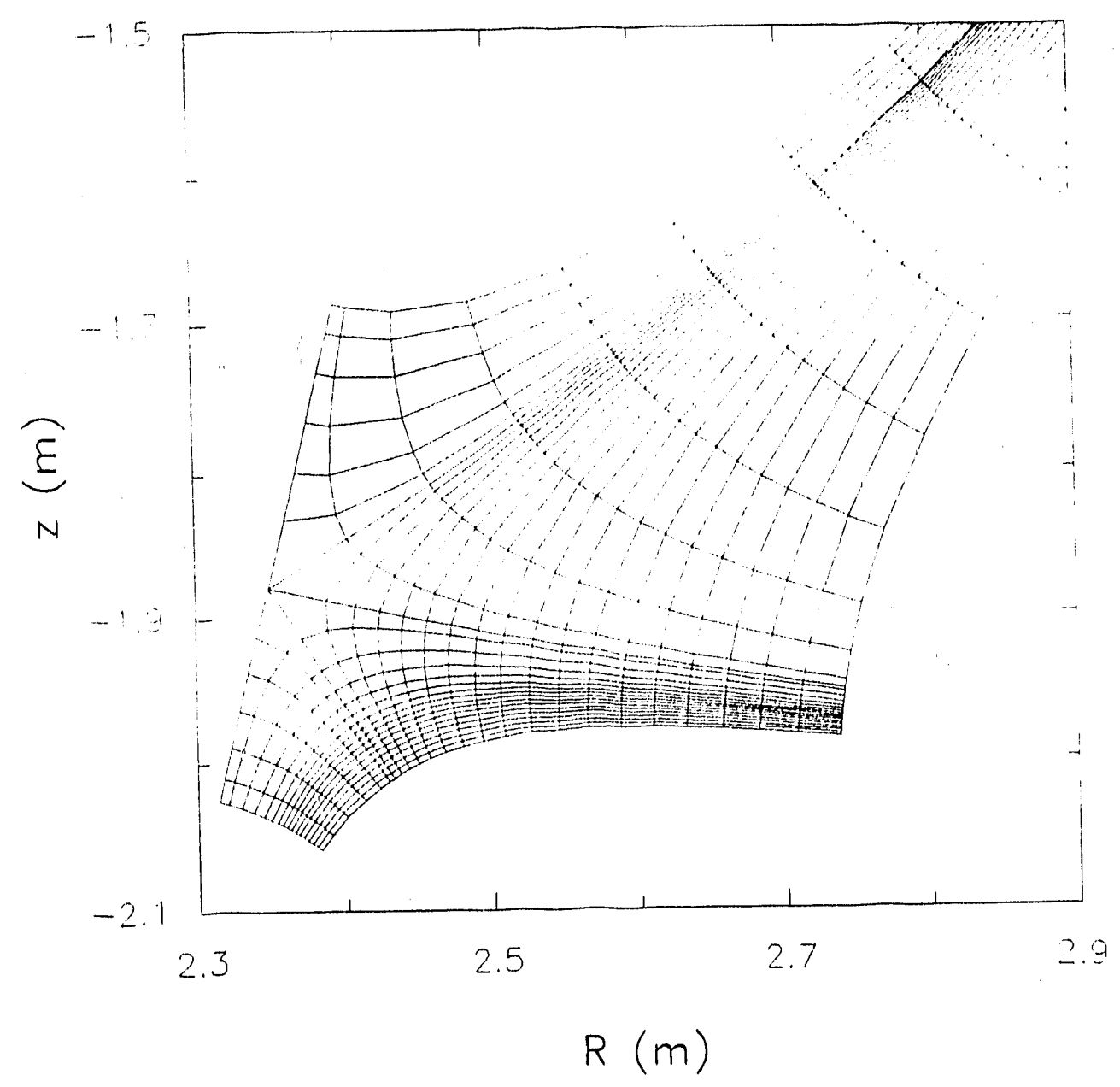

FIG. 4 


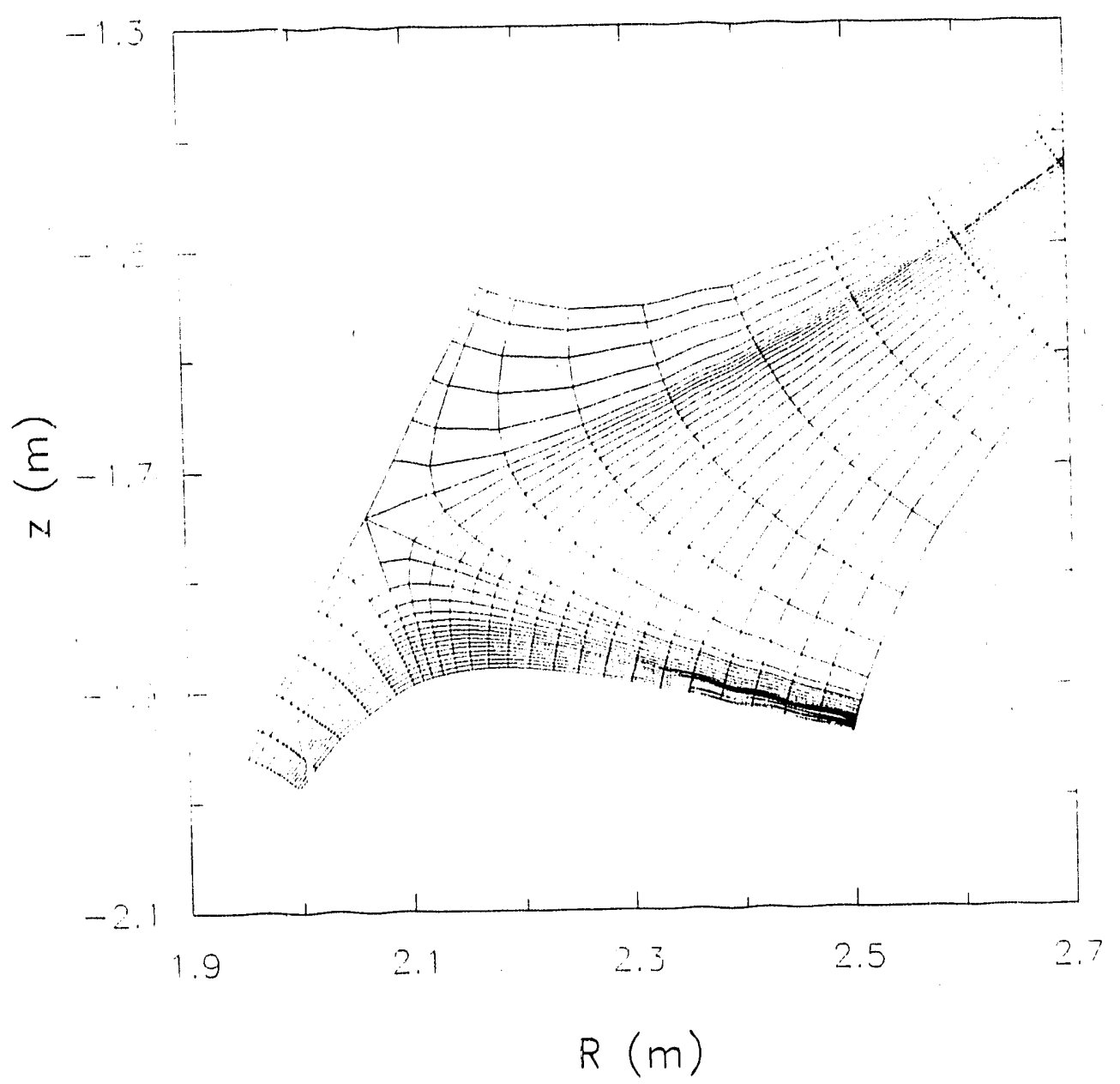

FIG. 5 

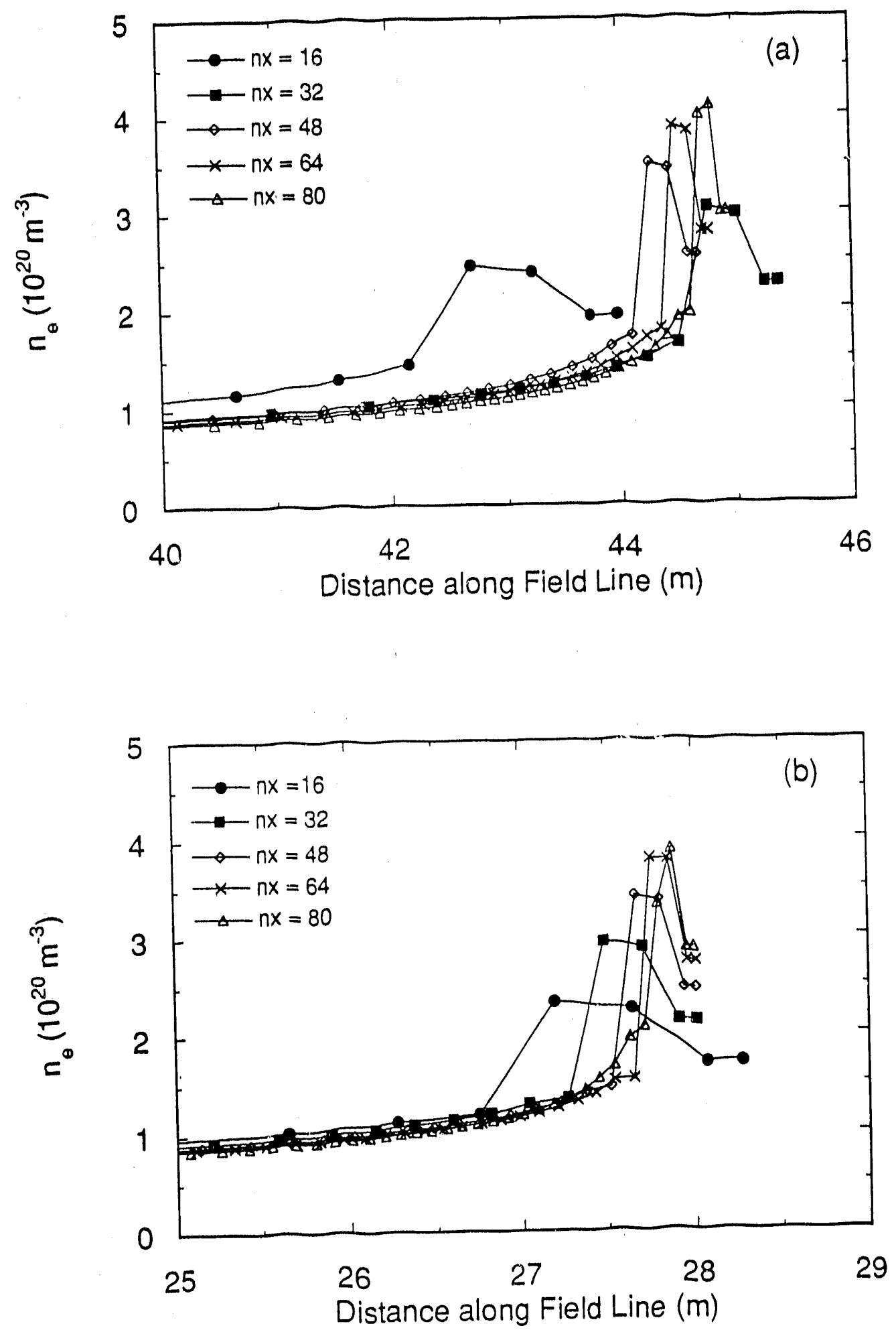

FIG. 6 

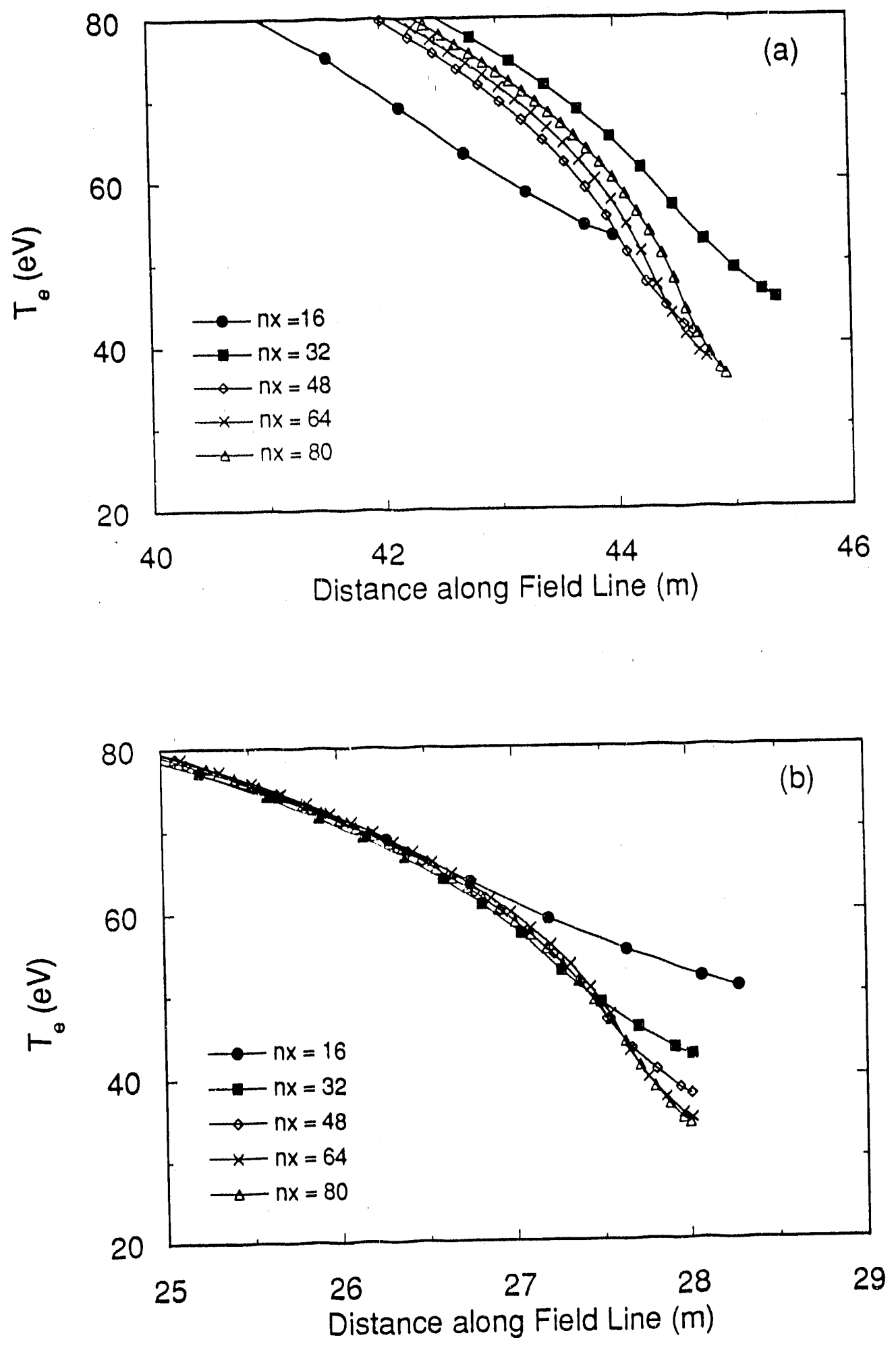

FIG. 7 

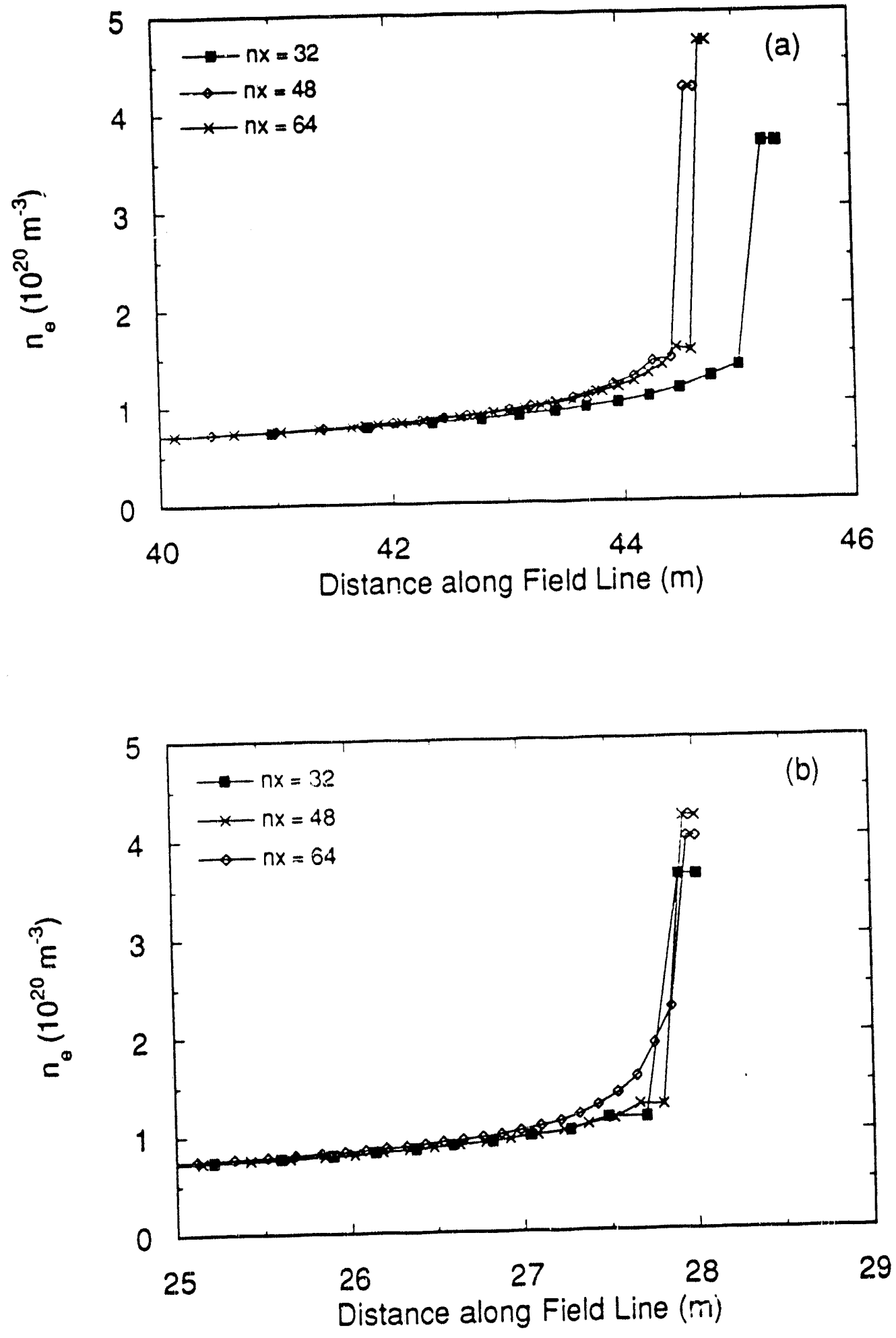

FIG. 8 

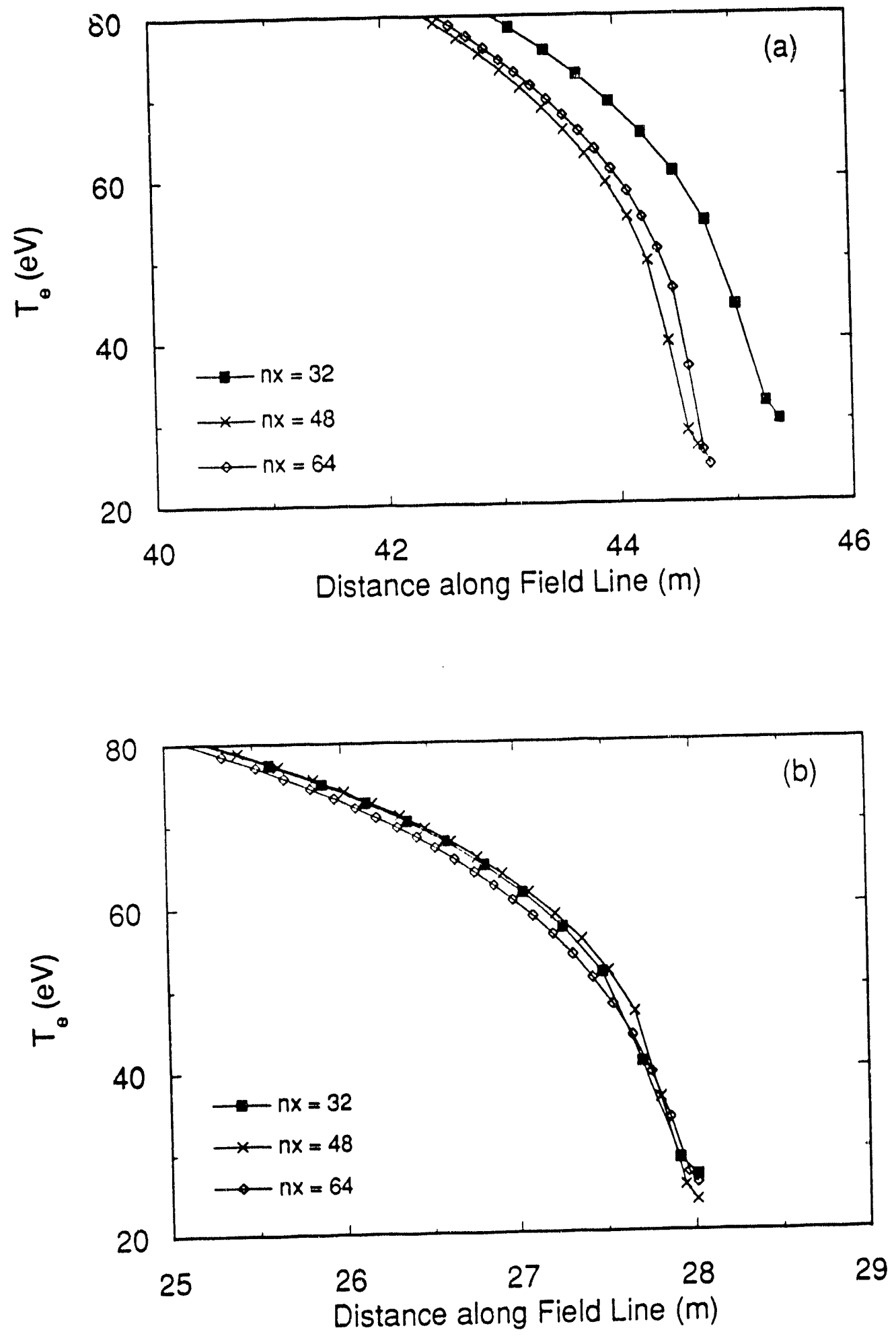

FIG. 9 


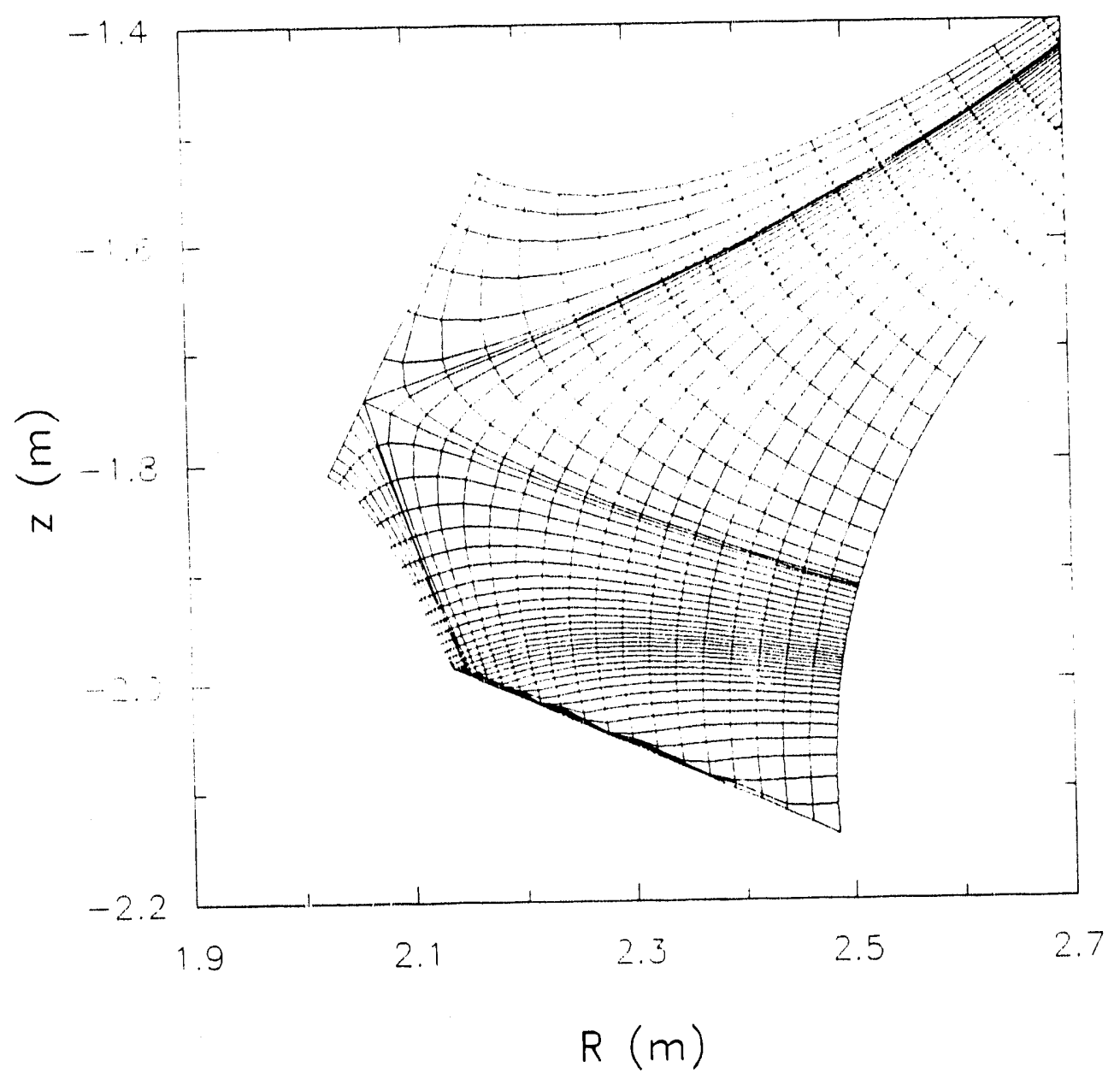

FIG. 10 
Dr. F. Prooloni, Univ, of Wollongong, AUSTRULLIA

Prof. M.H. Brennen, Univ. of Sydnoy, AUSTRALIA

Plasma Posoarch Lob., Austration Nat Univ., AUSTRALIA

Prol. I.A. Jones, Finders Univ, AUSTRALIA

Prot. F. Cap, Inst for Theoretical Physics, AUSTRIA

Prot. M. Heinder, Instiwt for Theoretieche Physik, AUSTRIA

Prof. M. Gooseens, Astronomisch Inetiuut, BELGIUM

Ecolo Roydo Nititairo, Lab. do Phy. Plasmos, BELGIUM

Commission-Europeen, DG. XII-Fueion Proo., BELGIUM

Prof. R. Bouciqus, Rijksuniveruibin Gent, BELGIUM

Dr. P.H. Sakenaka, Instibuto Fisica, BRUZZL

Instits Naciond Do Poequizas Espadicie-INPE, BRUZIL

Document Orice, Abonic Enorgy of Canada Ld., CANADA

Or. M.P. Bectynnekj, MPB Technotogies, Inc., CANADA

Dr. H.M. Skarsand, Univ. of Sackatchowen, CANADA

Prot. J. Toichmann, Univ. of Montreal, CANADA

Prot. S.R. Sreeniveeen, Univ. of Colgary, CANADA

Prof. T.W. Johnstion, INRS-Energio, CANADA

Dr. R. Botion, Contre canedien de tusion magnétique, CANADA

Or. C.R. James., Univ. of Aberta, CANADA

Dr. P. Lukte, Komensketio Universzita, CZECHOSLOVAKIA

Tho Librarian, Culham Leboratory, ENGLAND

Librery, R61, Puthertord Applaton Laboratory, ENGLAND

Mrs. S.A. Huxchineon, JET Librery, ENGLAND

Dr. S.C. Shame, Unir. of South Pacific, FIJI ISLANDS

P. Manonon, Univ. of Heisinki, FINLAND

Prof. M.N. Bussece, Ecolo Polytechnique, FRANCE

C. Moutrot, Leb. do Physique des Milioux loniater, FRANCE

J. Radot, CENCADARACHE - BaP 506, FRANCE

Prof. E. Economou, Univ. of Crote, GREECE

Ms. C. Pinni, Univ. of loamina, GREECE

Dr. T. Mud, Academy Bibliographic Ser., HONG KONG

Preprint Librery. Hungarian Acadomy of SCi. HUNGARY

Dr. B. DasGupta, Saha inst. of Nucter Physics, INDIA

Dr. P. Kaw, Inst. for Plasma Pesearch, INDIA

Dr. P. Roceneu, lered inst of Technotogy, ISRAEL

Librarien, Intemational Conter for Theo Physics. ITALY

Miss C. Do Palo, Associaziono EURATOMENEA, ITALY

Dr. G. Groseo, lethub di Ficica dal Plasma, ITALY

Prot. G. Rostanoni, lstivis Gas lonizzad Del Cnr, ITALY

Dr. H. Yeneto, Toehion Ras a Dovel Center, JAPAN
Prof. I. Kawakami, Hiroshma Univ., JAPAN

Prot. K. Nishikawa, Hiroshima Univ., JAPAN

Drector, Jepen Alomic Enorgy Rosearch Inst., JAPAN

Prot. S. Itoh, Kyushu Univ., JAPAN

Posearch into. C8., National ins tor Fusion Scionce, JAPAN

Prot. S. Tenaka, Kyoto Univ., JAPAN

Librany, Kyob Univ., JAPAN

Prot. N. Inowe, Univ. of Tokyo, LAPAN

Secretary, Plem Soction, Electrobchnical Lab., JAPAN

S. Mori, Tectnical Advicor, LAERI, JAPAN

or. O. Miturni, Kumanots inst. of Technology, JAPAN

J. Hyeon-Sook, Korva Abomic Energy Resoarch Inst, KOREA

D.I. Choi, The Korea Adv, Inst, of Sa. \& Toch., KOREA

Prof. B.S. Liby, Univ. of Waikato, NEW ZEALANO

Inst of Physicas. Chinese Acad SCI PEOPLE'S REP. OF CHINA

Libray, Inst. of Plasma Physics, PEOPLE'S REP. OF CHINA

Tsinghua Univ. Lbrary, PEOPLE'S REPUBLIC OF CHINA

2. L. S.W. Inat Phyeica, PEOPLE'S REPUBUC OF CHINA

Prot. J.A.C. Cabred, Intituro Suporior Tecnioo, PORTUGAL

Dr. O. Ponus, ALI CUZA Univ., ROMANIA

Dr. J. Villiors, Fusion Studios, AEC, S. AFRICA

Prot. M.A. Hevlborg, Univ. of Natui, S. AFRICA

Prot. D.E. Km, Pohang inst. of Sa. \& Tech., SO. KOREA

Prol. C.I.E.M.A.T. Fusion Division Library, SPAIN

Dr. L Swonto, Univ, of UMEA, SWEDEN

Librey, Royed inst. of Tectinology, SWEDEN

Prof. H. Wilhatmeon, Chaimers Univ. of Tech., SWEDEN

Contre Phys. Des Plasmas, Ecolo Potytoch, SWITZERLAND Bibliotheck, Inat. Voor Plasma-Fysican, THE NETHERLANDS

Asst Prot. Dr. S. Gakir, Middle Easi Tech. Univ., TURKEY

Dr. V.A. Guthilk, Sa. Res. Inst. Eloctrophys.I Apparatus, USSR

Dr. D.D. Ayubv, Siberian Branch of Academy of Sai., USSR

Dr. G.A. Eliceev, I.V. Kurchatov Inst, USSA

Librerien, Tho Uk.SSR Academy of Scionces, USSR

Dr. LM. Kowrizhnykh, Inst. of Generel Physics, USSR

Kentorectungeandeg GmbH, Zentrabibliothek, W. GERMANY

Bibliothok, Inst For Plasmatorectiung. W. GERMANY

Prot. K. Schindler, Ruhr-Univereith Bochum, W. GERMANY

Dr. F. Wegner, (ASOEX), Max-Planck-Inetitut, W. GERMANY

Librerien, Max-Plenck-Inetitur, W. GERMANY

Prot. R.K. Lanev, Inst of Ptycics, YUGOSLAVIA 

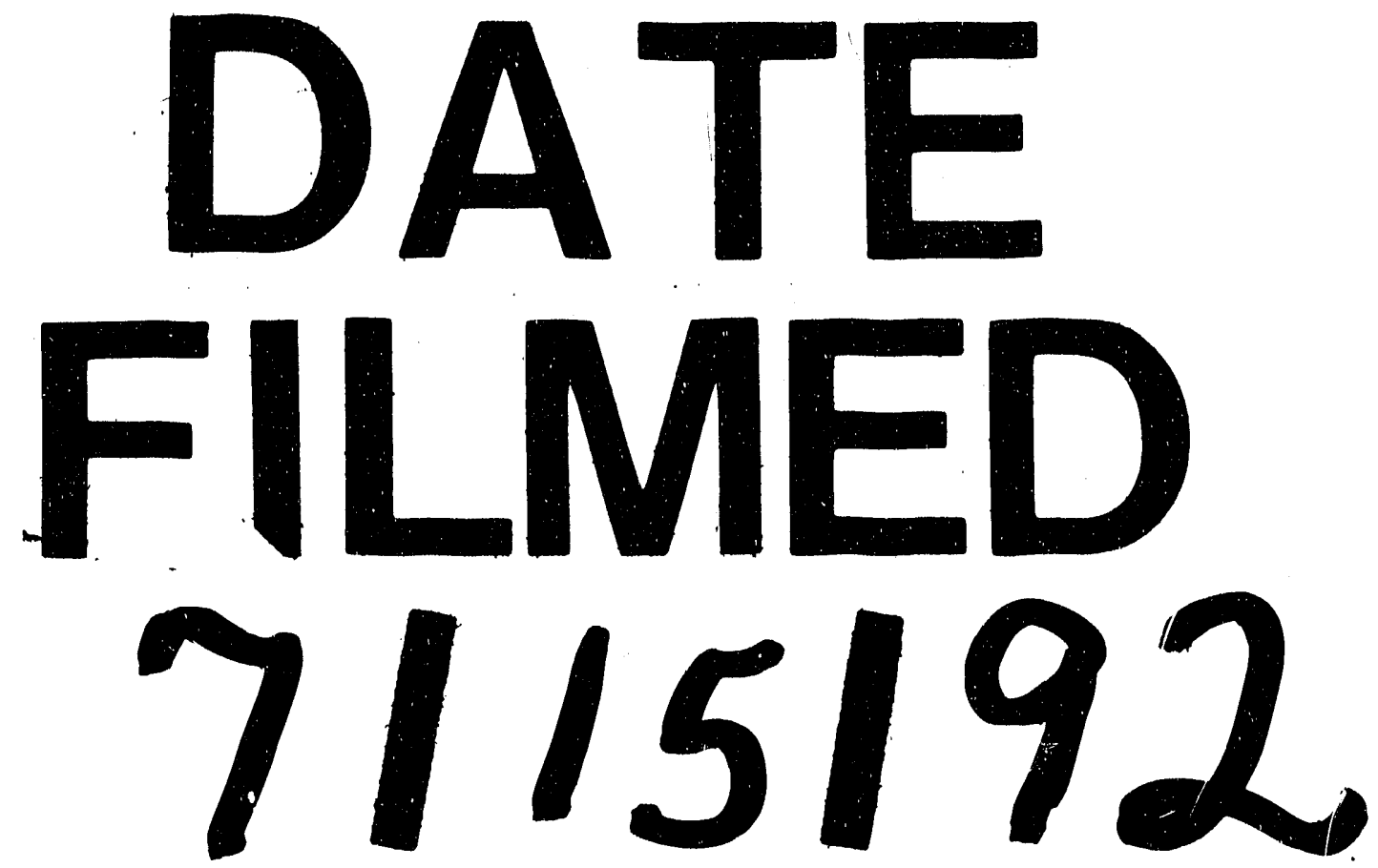


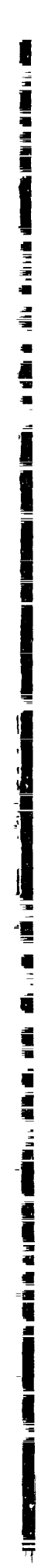

